\author{
BERTA LÓPEZ FERNÁNDEZ \\ Departamento de Geografía. Universidad de Oviedo
}

\title{
Poblamiento y declive demográfico en Asturias, 2000-2014
}

\section{RESUMEN}

Se analiza la variación relativa 2000-2014, así como la estructura por edad en 2014, de la población asturiana tomando como escala las dos unidades básicas del poblamiento, esto es, las 6.254 entidades singulares de población y las 863 parroquias habitadas, con el fin de entender los cambios que se avecinan en el grado de ocupación del territorio. El agudo envejecimiento y la escasez de habitantes caracterizan al $80 \%$ de las entidades singulares y constituyen un grave riesgo de despoblamiento.

\section{RÉSUMÉ}

Peuplement et déclin démographique en Asturies, 2000-2014.- On analyse la variation relative 2000-2014 et la structure par âge 2014 de la population des Asturies se reportant aux deux échelles basiques du peuplement, les 6.254 entités singulières de population et les 863 paroisses habitées, afin d'apercevoir les changements à venir dans le degré d'occupation du territoire. L'aigu vieillissement et l'insuffisance

$D$ los años en que el Departamento de Geografía de la Universidad de Oviedo ocupó las exiguas y precarias dependencias que tenía asignadas en el antiguo convento de San Vicente, hacia 1980, muchos guardamos el recuerdo de D. Francisco Quirós inclinado sobre la mesa común de la sala de lectura, o en un tablero de dibujo a la vista de quien pasara por allí, dedicado a la confección del mapa parroquial de Asturias. Innumerables hojas de papel vegetal, la colección de los mapas topográficos 1:50.000, los nomenclátores antiguos y modernos en los que se seguía conservando la memoria de la organización en parroquias del espacio regional, su insustituible Madoz constituían sus únicas herramientas. Y además, una capacidad de trabajo abrumadora que d'habitants caractérisent le $80 \%$ des entités singulières et constituent des graves risques de dépeuplement.

\section{ABSTRACT}

Settlement and demographic decline in Asturias, 2000-2014.- We analyse the relative variation 2000-2014 and the age structure in 2014 for the two smallest units of Asturian settlement, that is, the 6.254 singular entities and the 863 populated parishes, in order to anticipate approaching changes in the territory occupation. Acute ageing and lack of inhabitants characterize the $80 \%$ of singular entities, and constitute severe risks of disappearance.

Palabras Clave/Mots Clé/Keywords

Poblamiento, envejecimiento, entidades singulares, parroquias, Asturias. Peuplement, vieillissement, entités singulières, paroisses, Asturies. Settlement, ageing, singular entities, parishes, Asturias.

perseguía localizar para cada parroquia el mayor número posible de lugares y poder así dibujar los contornos de un mapa inexistente hasta entonces. En Asturias hay sólo 78 municipios, pero contienen casi novecientas parroquias, cuya delimitación exigió localizar un número ingente de términos, los citados en alguna de las fechas de la serie de los nomenclátores o de los mapas topográficos, cuya cifra quizá sobrepasase las ocho mil referencias.

Tanto trabajo no se enmarcaba en ningún proyecto de investigación tal como se entienden hoy, ni respondía a ningún encargo de una administración autonómica todavía inexistente, aunque años más tarde ésta editase el mapa (Quirós Linares, 1993). He aquí por el contrario sus razones: 
Hace ya varios años, al iniciarse en el Departamento de Geografía de Oviedo los primeros estudios sobre la geografía de la población asturiana, se nos hizo evidente la inadecuación del marco municipal como escala de observación para analizar la distribución de las densidades de población, dada la multiplicidad de entidades que la mayoría de los concejos asturianos alberga. A la vez, la permanencia de la parroquia como unidad censal, reflejada en los nomenclátores del Instituto Nacional de Estadística, nos decidió a tratar de basarnos en las mismas para obtener una base territorial que permitiese una cartografía de densidades de población más precisa que la que se puede obtener utilizando la base municipal.

En efecto, aunque el número de parroquias por concejo oscila entre 1 y 54, la media se sitúa en torno a once, lo que supone la posibilidad de obtener una representación de las densidades mucho más matizada. Para desarrollar esta posibilidad, y con el único objeto de aplicarlo al fin señalado, acometimos la confección de un mapa que incluyese la delimitación de las parroquias asturianas, operación que concluimos en 1981. (Quirós Linares, 1982, p. 79)

De modo que, además de las muchas ideas fructíferas que se deslizaban en las conversaciones habituales con él (algo que todavía ocurre después de tantos años), de los consejos que iluminaban el trecho que era necesario recorrer para lograr salir de algún atolladero propio de investigador inexperto y carente de las referencias precisas, del préstamo de innumerables libros de su biblioteca personal, D. Francisco Quirós ponía el resultado de su trabajo a disposición de quien quisiera hacer uso de él, dado que nunca se planteó realizar personalmente el mapa de densidades que menciona:

La cartografía a 1:50.000 se ha confeccionado separadamente para cada concejo y después se ha procedido a reducirla a 1:200.000 para elaborar un mapa de conjunto de toda Asturias [...]. Ambos mapas pueden ser consultados, y utilizados por quien lo desee, en la Sección de Geografía de la Universidad de Oviedo [...]. (Quirós Linares, 1982, p. 82).

Son bastantes las enseñanzas contenidas en estos párrafos, pero es obvio que el ejemplo personal que ofrecen constituye la lección más valiosa.

En las páginas que siguen, referidas a la evolución del poblamiento en Asturias a lo largo de los tres primeros lustros del siglo xxI, y que hacen un uso repetido del mapa parroquial del que venimos hablando, se aplican además otras dos provechosas enseñanzas de ese texto. En primer lugar, que el análisis de los fenómenos espaciales debe ceñirse lo más posible a la realidad observada, agrandando la escala hasta el límite de lo factible sin perder por ello la visión de conjunto. $\mathrm{Y}$ en segundo lugar, que las más de las veces no hay verdadero conocimiento geográfico sin una traducción cartográfica del mismo, es decir, si no hay mapas temáticos.

\section{LAS FUENTES ACTUALES PARA EL ESTUDIO DEL POBLAMIENTO}

En raras ocasiones se aborda el análisis del poblamiento a la escala que en realidad le es propia, la de las entidades de población, como no sea en el marco de estudios de carácter local. A ello contribuye la dificultad de conjugar el análisis simultáneo de lo muy grande y lo muy pequeño, de desentrañar lo particular y pretender transmitir una visión de síntesis, así como de manejar una elevada cantidad de datos, que paradójicamente no procede tanto de la riqueza de las fuentes estadísticas disponibles, que se reducen por el contrario a un nomenclátor muy parco en información, como del simple número de entidades que es preciso afrontar.

Por si lo anterior no fuera bastante disuasorio, pesa además la certeza de que la definición de tales entidades de población está sujeta a variaciones espaciales y temporales que hacen difícil su manejo, y que responden no sólo a la mutación del propio poblamiento sino también a la extraordinaria variedad de lo que debe de entenderse por lugar habitado.

De esta manera, la constatación repetida del retroceso demográfico de muchas regiones españolas, entre ellas la asturiana, va acompañada de una fragilidad creciente del poblamiento que sin embargo resulta difícil poner de manifiesto en toda su complejidad e intensidad. Con frecuencia, allí donde los municipios no poseen demasiadas entidades de población, o no son muy extensos, la escala de análisis municipal permite salir del paso. Pero como ya se ha visto, esa solución no es satisfactoria en el caso de Asturias, donde la ocupación del territorio se caracteriza, como en Galicia, por una extraordinaria proliferación de los lugares habitados en el marco administrativo de muy pocos municipios.

Tradicionalmente, la de las entidades de población era una escala que sólo estaba disponible en los nomenclátores oficiales, es decir, los asociados a los censos decenales correspondientes, si bien en las dos últimas décadas del siglo xx ya habían comenzado a obtener también sus datos de los padrones municipales de fecha intercensal (1986 y 1996), aumentando de este modo su frecuencia. Con la implantación del Padrón Continuo a partir de 1996, al tiempo que se publican las Revisiones Padronales referidas al 1 de enero de cada año, lo hace igualmente su parejo listado de población por entidades, es decir, el nuevo Nomenclátor, con lo que desde 2000 éste ha pasado a ser anual. Pero además, la consulta en línea del Padrón Municipal de Habitantes a través del procedimiento de confección personalizada de tablas permite la 
elección de escalas inframunicipales, de tal manera que es posible obtener datos no sólo para los distritos y secciones censales, como sucede con los censos recientes, sino también para las entidades de población. Este recurso sólo está disponible para 2003 y fechas posteriores, una vez perfeccionada la gestión continua del Padrón. De este modo se abren nuevas posibilidades en el análisis del poblamiento, limitadas, eso sí, por la parquedad actual de los padrones, que tan sólo recogen el nombre y apellidos de los empadronados, el sexo, su domicilio, la nacionalidad y el lugar y la fecha de nacimiento, además del DNI o documento similar. Quítese lo primero y lo último, y se obtendrá lo que puede dar de sí este documento administrativo en su faceta de fuente estadística, muy constreñida por la normativa legal relativa a la protección de datos.

Dado que vamos a hacer uso de esta escala inframunicipal, es preciso conocer que, como se advierte en la nota metodológica del Nomenclátor, las entidades singulares no poseen carácter oficial (como tampoco las colectivas, que únicamente tienen todavía un uso corriente en Galicia y Asturias ${ }^{1}$ ). Por lo general unas y otras hunden sus raíces en una larga tradición, de modo que el INE ha rehuido imponer su fijación, delegándola en los ayuntamientos involucrados. De este modo, la determinación del listado municipal de entidades singulares constituye una competencia exclusiva del Ayuntamiento correspondiente, para lo cual no hay impedimento alguno en cuanto a la forma o el tamaño mínimo del lugar habitado:

Se entiende por Entidad singular de población cualquier área habitable del término municipal, habitada o excepcionalmente deshabitada, claramente diferenciada dentro del mismo, y que es conocida por una denominación específica que la identifica sin posibilidad de confusión. Un área se considera habitable cuando existen en la misma viviendas habitadas o en condiciones de serlo.

Existe pues margen para una cierta discrecionalidad en la confección del listado de lugares habitados por parte de los ayuntamientos, o concejos como se denominan en Asturias. Más estricta es sin embargo la calificación de sus porciones internas, compuestas de uno o más núcleos

\footnotetext{
${ }^{1}$ En alguna otra provincia el Nomenclátor recoge también la existencia de entidades colectivas, pero no revisten un carácter general. Así por ejemplo, en la provincia de Murcia, varios municipios extensos poseen pedanías (Murcia, Lorca, Cartagena, Fuente-Álamo, Caravaca de la Cruz y otros), pero esta organización inframunicipal no es generalizable a toda la provincia e incluso, allí donde existe, puede no aplicarse a todo el territorio municipal. Cuando en Asturias sucede esto último, resulta sin embargo excepcional: Langreo como entidad singular de población en el municipio de su mismo nombre, o Raíces Nuevo y Coto Carcedo en el de Castrillón, no se encuadran en ninguna parroquia y, como ellos, sólo existen 5 pequeñas entidades más en el mismo concejo de Castrillón.
}

y de una fracción en diseminado. Para los núcleos se requiere un mínimo de diez edificaciones dispuestas de manera relativamente densa, o al menos de cincuenta habitantes, considerando como diseminado todas las edificaciones o viviendas que no entren en ese marco. De este modo, cabe la posibilidad de que, además de un cierto número de viviendas en diseminado acompañando a las dispuestas de forma más compacta, algunas entidades singulares aparezcan calificadas al completo como diseminado, careciendo de núcleo ninguno, bien por la laxitud de la disposición de sus edificios, bien por la insuficiencia numérica de las viviendas o de las personas.

Hechas estas aclaraciones sobre los criterios actuales de definición de las unidades básicas de información que comprende el Nomenclátor, es necesario referirse ahora al propio listado de lugares habitados, aquejado de la mala fama de ser inconstante y voluble a lo largo de la serie de los censos, desde 1857 , y por tanto de uso casi imposible en los análisis temporales. No obstante, la realidad actual es otra, pues desde el Censo de 1981 disponemos de un listado que, aunque vivo y por consiguiente mudable, está realizado con la pretensión de que perdure en sus líneas generales, a fin de facilitar el seguimiento diacrónico. En el Nomenclátor de 1981 se organiza una codificación rigurosa, por orden alfabético, de las entidades colectivas de cada concejo y, dentro de ellas, de las singulares. En el de 1996 se pretende, sin mucho acierto todavía, codificar también los núcleos y los diseminados, lo que se logra a partir del año 2000 con la implantación de un código de once dígitos. Con ello se persigue una identificación relativamente segura, que esté a salvo de los cambios que puedan producirse tanto en el nombre como en el número de las unidades recogidas.

A modo de ejemplo de la codificación a escala inferior a la parroquia, y de la manera en que suelen aparecer las unidades espaciales correspondientes, véanse estas cuatro entidades singulares del concejo de Castrillón (Cuadro 1). Campiello y Camino Quiloño, pertenecientes a la parroquia de Laspra, representan los dos casos más frecuentes en Asturias, el primero consta de un solo núcleo, y el segundo únicamente contiene viviendas en diseminado. Algo más complejo es el caso de la entidad singular de La Banda, en la parroquia de Santiago del Monte, compuesta de una parte en núcleo y de otra en diseminado. La entidad singular de San Martín de Laspra, por su parte, consta en la actualidad de nueve núcleos, y constituye una situación sumamente rara en Asturias.

Casos como este último, no obstante, ocurren desde hace varias décadas en aquellas regiones donde el crecimiento periurbano y la proliferación de usos residencia- 
CUADRO 1. Ejemplo de organización actual en el Nomenclátor de las entidades inframunicipales

\begin{tabular}{|c|c|c|c|c|c|}
\hline Provincia & Municipio & Entidad Colectiva & Entidad singular & Núcleos/Diseminado & Código \\
\hline \multirow[t]{2}{*}{33 Asturias } & 016 Castrillón & 02 Laspra & 21 Campiello & & 33016022100 \\
\hline & & & & 01 Campiello & 33016022101 \\
\hline \multirow[t]{10}{*}{33 Asturias } & 016 Castrillón & 02 Laspra & 23 San Martín de Laspra & & 33016022300 \\
\hline & & & & 01 Alvaré & 33016022301 \\
\hline & & & & 02 Cabildo (El) & 33016022302 \\
\hline & & & & 03 Cueto (El) & 33016022303 \\
\hline & & & & 04 Fondón & 33016022304 \\
\hline & & & & 05 Gallo (El) & 33016022305 \\
\hline & & & & 06 Gabariza & 33016022306 \\
\hline & & & & 07 Navalón & 33016022307 \\
\hline & & & & 08 Pedreras (Las) & 33016022308 \\
\hline & & & & 10 Vallina (La) & 33016022310 \\
\hline \multirow[t]{2}{*}{33 Asturias } & 016 Castrillón & 02 Laspra & 24 Camino Quiloño & & 33016022400 \\
\hline & & & & $99 *$ Diseminado* & 33016022499 \\
\hline \multirow[t]{3}{*}{33 Asturias } & 016 Castrillón & 04 Santiago del Monte & 01 Banda (La) & & 33016040100 \\
\hline & & & & 01 Banda (La) & 33016040101 \\
\hline & & & & $99 *$ Diseminado* & 33016040199 \\
\hline
\end{tabular}

Fuente: INE, Nomenclátor 2014

les y de ocio han dado origen a una constelación de urbanizaciones, polígonos industriales y formas análogas de ocupación del espacio, que con frecuencia tienen su reflejo en el Nomenclátor bajo la forma de núcleos o diseminados anejos a las entidades singulares preexistentes ${ }^{2}$.

Dado que el objeto de estas páginas no es la caracterización morfológica del hábitat en Asturias, lo que desborda con creces las dimensiones de un trabajo de esta naturaleza, ni tampoco la distribución detallada de la población asturiana, algo que ya se ha realizado en alguna ocasión ${ }^{3}$, se ha decidido adoptar la escala espacial de las entidades singulares de población como escala mínima de trabajo, sin ir más allá en la consideración interna de las entidades (es decir, desestimando la distinción entre núcleo y diseminado), y usar la de las parroquias como escala para la representación cartográfica de la información estudiada, habida cuenta de la dificultad de apreciar los resultados del análisis procediendo a la

\footnotetext{
${ }^{2}$ Consúltese a modo de ejemplo el Nomenclátor correspondiente a algunos municipios litorales de la provincia de Alicante.

${ }^{3}$ Una representación de la distribución real de la población asturiana tomando como base las entidades de población se publicó en el Atlas escolar de Asturias (Fernández Cuesta y otros, 2005, pp. 118-119) en tanto que una representación cartográfica completa de los Nomenclátores de 1900, 1970, 1981, 1996 y 2007 para toda España se encuentra en el Atlas temático de España (López Fernández, 2011,pp. 24-33).
}

representación individual de las 6.254 entidades singulares de población.

El objetivo de estas páginas, en fin, es el de poner de manifiesto la evolución reciente de las unidades básicas del poblamiento en Asturias, las entidades de población y, además, apreciar en qué medida el desbaratamiento actual de las estructuras demográficas compromete su futuro cercano. Por ello, no sólo se han obtenido del Nomenclátor las cifras de población del periodo 2000-2014, sino también las relativas a su composición demográfica por edades correspondientes a la actualización del $\mathrm{Pa}$ drón Municipal con fecha de 1 de enero de 2014.

\section{DENSIDAD Y EVOLUCIÓN DEL POBLAMIENTO ASTURIANO, 2000-2014}

La mera cifra del total de entidades singulares que recoge el Nomenclátor de 2014 para Asturias sugiere un entramado de ocupación del territorio denso y regular, un patrón de poblamiento característico que Asturias compartiría de forma más o menos imprecisa con el resto de las regiones del norte y del noroeste peninsular. En ese listado se registran 6.254 entidades habitadas, pero la cifra se eleva todavía a 6.944 si también se tienen en cuenta aquéllas que aparecen despobladas. Trátese de una canti- 


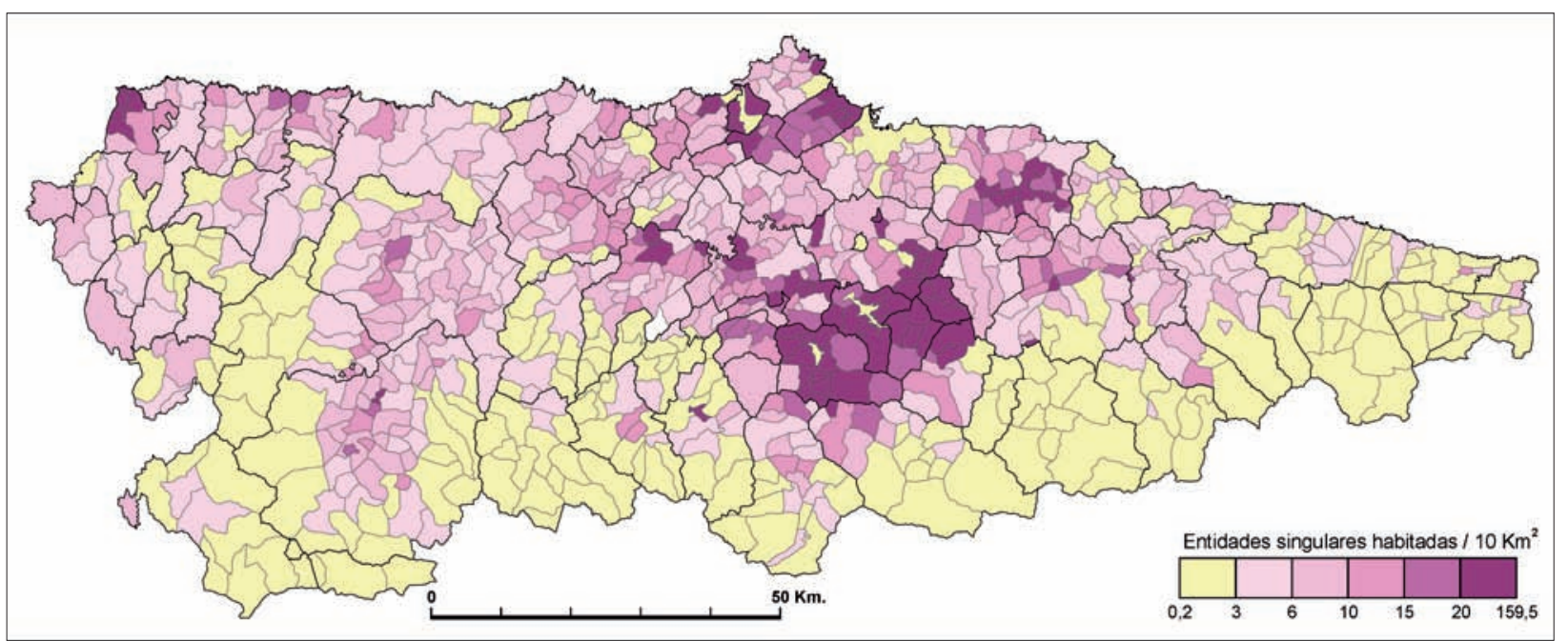

FIG. 1: Densidad de entidades singulares por parroquias, 2014.

dad o de la otra (la abultada diferencia entre ambas será objeto de comentarios posteriores), arrojan una densidad por superficie muy alta, de en torno a 6 entidades por cada $10 \mathrm{~km}^{2}$. No obstante, esa cifra resulta estar todavía lejos de las que se pueden observar en la fachada litoral gallega, pues en La Coruña y en Pontevedra se calculan más de 13 entidades singulares por cada $10 \mathrm{~km}^{2}$, y en Lugo 10. Por contraste, Cantabria y Guipúzcoa no llegan a 2 entidades singulares por $10 \mathrm{~km}^{2}$, y Vizcaya no alcanza la cifra de 3 .

Como es lógico, mayores diferencias se encuentran cuando se agranda la escala y se consideran las densidades dentro de la propia región (Fig. 1), pues la cifra de entidades singulares por $10 \mathrm{~km}^{2}$, que en la parroquia de Mieres Extrarradio alcanza la exorbitante cantidad de 159,5 si se consideran sólo las pobladas, y de 215 si se incluyen también las deshabitadas, muestra por el otro extremo un bajo grado de ocupación en muchas parroquias situadas en los contrafuertes de la Cordillera: menos de 0,3 entidades pobladas en las parroquias ponguetas de Sobrefoz y Casielles, o en las cabraliegas de Tielve y Sotres, o en la somedana Villar de Vildas. En general, todas las áreas de montaña, y no sólo las más elevadas de la Cordillera, presentan un poblamiento reducido, con menos de 3 entidades por cada $10 \mathrm{~km}^{2}$, y así ocurre en los cordales entre el Eo y el Navia, o entre éste y el Narcea, en el occidente de la región, y en muchos lugares de la montaña central. En el extremo regional opuesto, la cercanía a la costa de los relieves elevados explica, quizá sólo de forma parcial, las bajas densidades que abundan al este del concejo de Ribadesella.

Las densidades en torno a la media asturiana, las comprendidas a grandes rasgos entre 3 y 10 entidades $/ 10$ $\mathrm{km}^{2}$, se encuentran en las áreas de altitud menor y una abundancia mayor de espacios aprovechables para la agricultura, como el valle del Narcea, la baja montaña en general y amplios sectores del surco prelitoral y de las marinas.

Las inmediaciones de las áreas urbanas muestran una mayor concentración de entidades por parroquia, por encima de 15 entidades $/ 10 \mathrm{~km}^{2}$. Los concejos de Castrillón, Corvera y Carreño, en el litoral cercano al cabo Peñas, conocen una periurbanización creciente inducida por su cercanía de Avilés y Gijón, que se ha sobreimpuesto a un poblamiento ya denso en origen. De manera parecida ocurre con las parroquias del concejo de Oviedo que forman una aureola al sur de la capital, y con las situadas en torno a Villaviciosa.

Pero lo más llamativo del mapa resulta ser la elevada continuidad espacial de fortísimas densidades en las cuencas hulleras del área central, ocupando al completo los concejos de Mieres, Langreo, San Martín del Rey Aurelio y Bimenes, y de manera parcial los de Laviana y Siero. Allí, al poblamiento rural preexistente, transformado en muchas ocasiones en residencia obrera, se ha añadido desde la segunda mitad del siglo XIX una multitud de barriadas y grupos dispersos de viviendas, situados más o menos lejos de los centros urbanos, pero siempre buscando la cercanía de los pozos (Fernández García y Morales Matos, 1983, p. 277). La traslación íntegra y directa al Nomenclátor de tales formas de poblamiento disperso quizá guarde relación con lo reciente de su origen, pues lo cierto es que, al menos sobre el plano, algunas aldeas de disposición abierta y muy laxa de las marinas ofrecen semejanzas formales con cierto poblamiento 


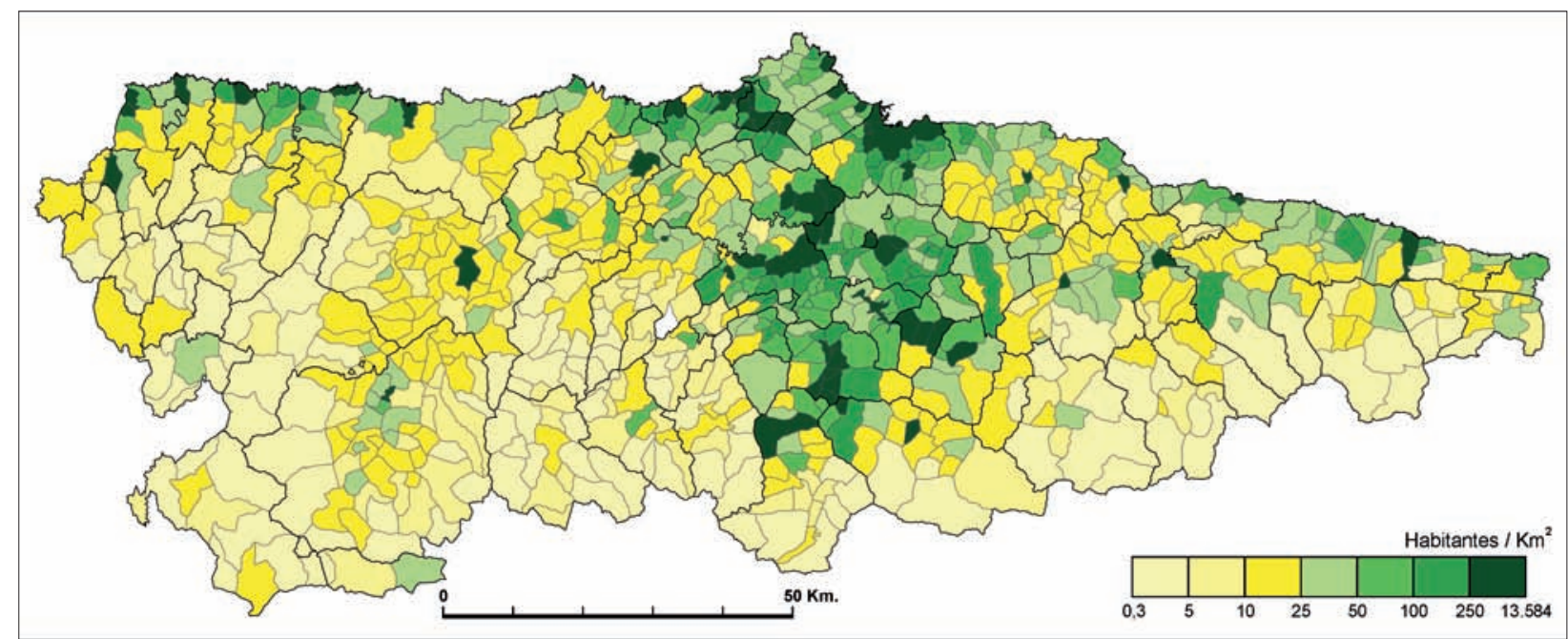

FIG. 2: Densidad de población por parroquias, 2014.

denso de las áreas mineras, pero la diferencia estriba en que en aquéllas los conjuntos menores se consideran simples barrios, y así se denominan localmente, sin llegar a ascender en la fuente estadística al rango de entidades singulares, como ocurre en las cuencas.

Tal es la acumulación de entidades singulares en estos concejos hulleros que si restáramos de la cifra total registrada en Asturias la correspondiente a la suma de sólo tres concejos, los de Langreo, Mieres y San Martín del Rey Aurelio, que por sí solos reúnen la desmesurada cifra de 1.056 entidades singulares de población, detraeríamos un $15 \%$ del total. Si hiciéramos lo mismo considerando únicamente las entidades habitadas en 2014, la merma seguiría siendo notable, de un 13,4\%. Lo dicho sirve para recalcar cómo este rasgo local del poblamiento asturiano pesa sobre la caracterización global del mismo, pero también alerta sobre algunos aspectos relativos al propio listado de entidades despobladas.

Vista la densidad del poblamiento, herencia de siglos de colonización agraria y de otros usos más recientes del territorio, cabe preguntarse si todavía hoy mantiene una correspondencia con la densidad de población, habiendo transcurrido ya muchas décadas desde mediados del siglo XIX caracterizadas por el declive del sector agrario, la industrialización y posterior crisis de la minería y de la industria, la emigración rural y su paralela concentración urbana. Habiéndose disipado, en suma, buena parte de las razones que explicaron su origen.

Tras la fachada de una correspondencia en sus grandes rasgos, las densidades de población muestran en realidad, como no podía ser de otra manera, la preeminencia demográfica de las ciudades, pues en el mapa correspon- diente (Fig. 2) se lee ante todo la disposición y estructura de la red urbana asturiana. Los núcleos mayores de área central, especialmente el triángulo Oviedo-Gijón y Avilés aparecen rodeados de aureolas periurbanas en las que, además de las actividades terciarias e industriales, ha ido apareciendo un uso residencial de baja densidad, consecuencia de la disociación entre el lugar de trabajo y el de residencia, que aprovecha la proliferación de vías de alta capacidad y el aumento de accesibilidad espacial dentro del área central (Fernández García, 2007, pp. 7278). Así, el litoral entre Castrillón y Villaviciosa, el surco entre Oviedo y Siero, además de los valles mineros del Caudal y del Nalón, presentan regularmente densidades por encima de los 50 habitantes por $\mathrm{km}^{2}$.

Las piezas de rango intermedio de la red urbana parecen ejercer también un cierto papel fijador de población en su entorno inmediato, fácilmente perceptible cuando su parroquia es de extensión reducida, como en el caso de algunas villas del interior: Grado, Cangas del Narcea o también el tramo de surco prelitoral comprendido entre Infiesto y Cangas de Onís. Igualmente se aprecia su papel vertebrador cuando su influencia urbana se conjuga con el crecimiento de las segundas residencias y el basculamiento general de la población desde el interior hacia las parroquias de la marina, como ocurre en el tramo costero occidental entre Vegadeo y Luarca, o entre Colunga y Llanes, en la marina oriental. Las cabeceras de concejo más pequeñas, o situadas en entornos muy despoblados, constituyen por el contrario meros islotes, como Tineo, Teverga y Cabañaquinta, entre otras.

El resto del espacio regional, por su parte, presenta un grado de ocupación muy bajo, pues un $28 \%$ de las parro- 
CUADRo 2. Variación del tamaño demográfico de las entidades singulares de población entre 2000 y 2014

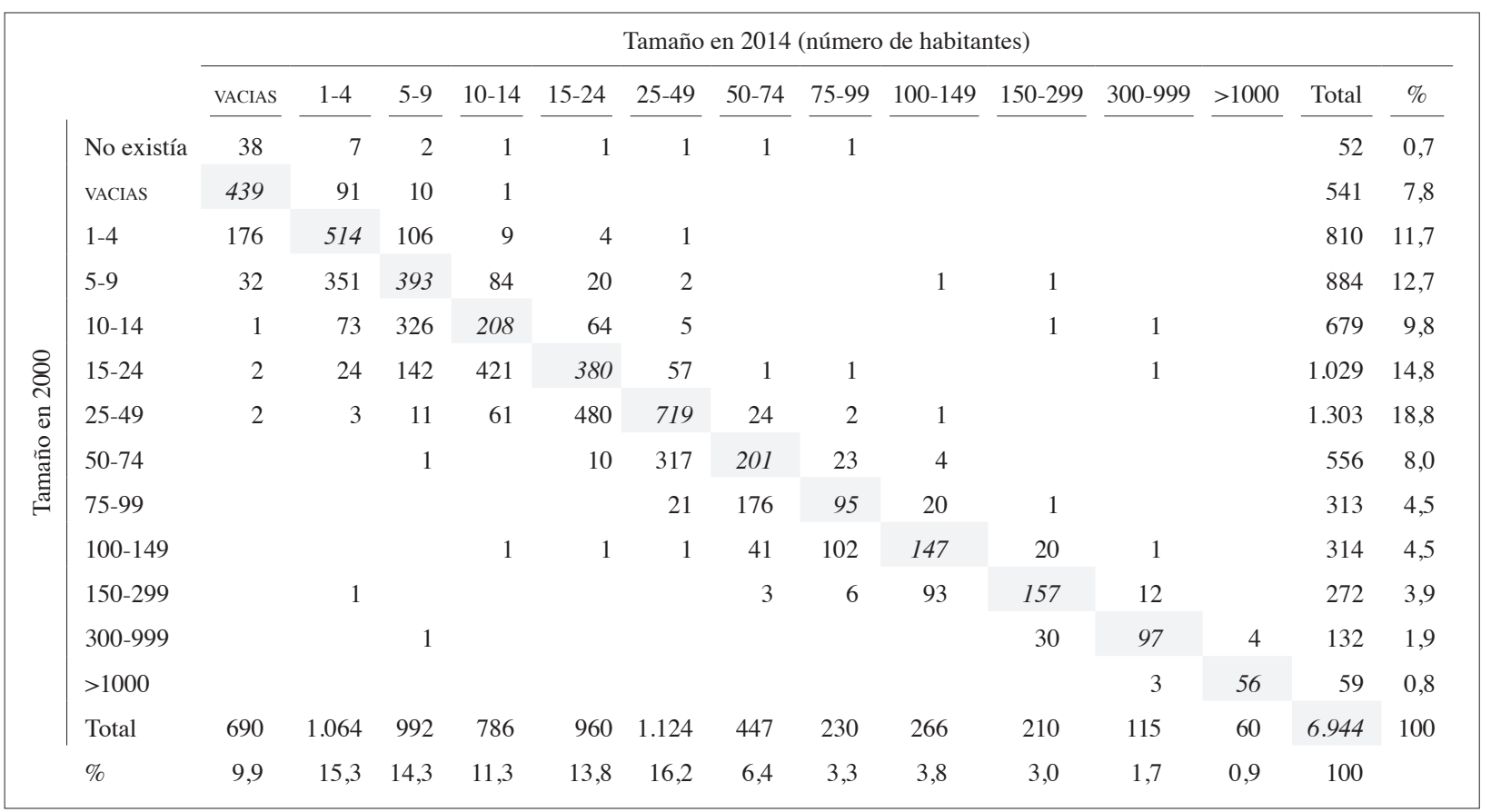

quias cuentan con una densidad inferior a diez habitantes por kilómetro cuadrado ${ }^{4}$; éstos son los espacios que vienen a coincidir con las áreas en las que la densidad del poblamiento ha sido tradicionalmente escasa. En otro 28 $\%$ de las parroquias las densidades oscilan entre 10 y 25 habitantes, pese a contar ya con un número de entidades relativamente alto, de modo que se puede identificar a éstos como los espacios agrarios aquejados de una mayor despoblación.

Esa discrepancia espacial entre densidad de poblamiento y densidad de población precisa pues del análisis del tamaño de las entidades singulares, así como de su evolución temporal, por más que el corto lapso de tiempo que cubren estas páginas, de apenas tres lustros, sea insuficiente para explicar en su totalidad la brecha abierta entre ambas distribuciones. Con ese objeto, y dado que la realización de índices de variación relativa se vería muy afectado por la amplitud del rango de magnitudes absolutas de las entidades singulares, se ha realizado en su lugar una matriz de evolución 2000-2014. En ella se ha repartido en tramos, tanto para una fecha como para la

\footnotetext{
${ }^{4}$ En 1877 no había en Asturias ningún municipio con una densidad de población inferior a esa cifra, ni aun los de montaña. Véase Pérez González (1983, p. 246).
}

otra, el tamaño demográfico de las entidades singulares, y además se ha registrado la variación de tamaño a lo largo del periodo (Cuadro 2$)^{5}$.

Una primera lectura de dicho cuadro de paso es relativamente tranquilizadora, pues muestra dos signos de permanencia. De un lado se aprecia que a lo largo de la diagonal de la matriz se disponen 3.400 entidades singulares, lo que significa que 1 de cada 2 entidades singulares de población no ha variado de tramo en estos años; en segundo lugar, en la distribución de frecuencias de ambas fechas se aprecia cómo el tamaño más frecuente para las entidades singulares, la moda, se mantiene en el grupo de entre 25 y 50 habitantes.

Una segunda lectura, sin embargo, proporciona varios motivos de inquietud, uno de ellos es la generalización de las pérdidas, pues más del $80 \%$ de las entidades que sí han variado de tamaño han perdido población suficiente como para caer al tramo inmediato inferior, o aún más allá; otro rasgo preocupante es la resultante debilidad demográfica de las entidades, pues mientras que en 2000 el

\footnotetext{
${ }^{5}$ Las pocas entidades singulares cuya evolución 2000-2014 se aleja a cierta distancia de la diagonal de la matriz son lugares situados en la periferia de las ciudades, afectados por mutaciones bruscas del espacio urbano. También cabe mencionar la recomposición de alguna parroquia, con su baile de entidades (caso de Carbayín en Siero).
} 
segundo intervalo más frecuente era el situado por debajo de la moda (es decir, el de entre 15 y 25 habitantes), en 2014 ese lugar lo ocupa el de las entidades de tamaño diminuto, inferior a 5 habitantes y por consiguiente en grave riesgo de despoblación. Quiere esto decir que si a comienzos de este siglo 1 de cada 4 entidades singulares habitadas tenía menos de 10 habitantes, quince años más tarde esa proporción ha subido a casi 1 de cada 3 , sumando un total de 2.056 entidades singulares cuyo simple tamaño justifica considerarlas en situación muy vulnerable en el actual marco recesivo.

Apenas sufre cambios, sin embargo, el número de las entidades que podríamos considerar urbanas, por sobrepasar los 1.000 habitantes. Degaña, Tuilla y Lastres pierden esa cifra y su lugar lo ocupan en 2014 cuatro entidades costeras, de los concejos de Corvera (Los Campos y Entrevías), Gijón (Vega de Abajo) y Soto del Barco (Soto, cuyo espacio urbano parece haber sido redefinido absorbiendo algunas entidades adyacentes). Tampoco varía demasiado el peso demográfico de ese reducido grupo de unas 60 entidades, como no sea un ligero incremento, pues tanto en una fecha como en la otra albergan a 3 de cada 4 asturianos.

Por el otro extremo de la matriz de variación, se observa un aumento de las entidades vacías, desde la elevada cifra de 541 en 2000 a la muy llamativa de 690 en la fecha más cercana. Y aunque el cuadro también muestra que esa situación puede no ser definitiva y hay lugares que consiguen recuperar algún habitante, esa cantidad de entidades despobladas constituye un rasgo muy sobresaliente, por lo que se impone realizar a algunas observaciones.

Por un lado, resulta lógico que el número de despoblados guarde correspondencia con la cifra general de entidades, y así las provincias de Lugo, Asturias y La Coruña contienen en 2014 respectivamente 693, 690 y 623 entidades vacías, agrupando por si solas los dos tercios del total español de lugares despoblados (3.229 entidades para toda España en el Nomenclátor de 2014). Por otro lado, cabe decir que cualquiera de las dos cifras de despoblados asturianos, bien sea la de 2000 bien la de 2014, no resume ni de lejos el proceso del despoblamiento, que en muchos casos data de mediados del siglo pasado, cuando no de finales del siglo XIX. Puesto que la confección del listado actual es de 1981, muchos de los despoblados anteriores han ido desapareciendo discretamente de las sucesivas relaciones de los nomenclátores, y así algunas entidades de montaña, que ocupaban espacios marginales incluso con los parámetros de una ocupación del espacio antigua, ajena por tanto a los conceptos de accesibilidad y rentabilidad actuales, o también las brañas vaqueiras, representativas de modos de vida desaparecidos, han ido desvaneciéndose de las estadísticas y cayendo en el olvido, de modo que la confección de un listado real y completo exigiría la revisión de la serie entera de los nomenclátores históricos, y no solo de los actuales, así como un repaso de la cartografía topográfica y un atento trabajo de campo. Todo ello sin considerar nada más que los lugares habitados de un cierto tamaño, y no los barrios periféricos o grupos aislados de viviendas nacidos con frecuencia en las últimas fases de roturación e incorporación al terrazgo preexistente de nuevos espacios, los tantas veces llamados «bravos».

Pero además, en la consideración de la cifra de despoblados es necesario tener en cuenta otras cuestiones. Se ha dicho ya que la confección del listado es responsabilidad de los ayuntamientos, y que constituye un listado vivo pues continúan incorporándose entidades, lo que en ciertas ocasiones en efecto responde a la consolidación de nuevos espacios residenciales, pero que en otras carece por completo de lógica alguna. Repárese por ejemplo en que, de las 52 entidades asturianas añadidas al Nomenclátor entre 2000 y 2014, 42 corresponden únicamente al concejo de Mieres y que, por añadidura, 35 de ellas han nacido ya vacías y nunca han tenido ni un solo habitante empadronado, contraviniendo las instrucciones del organismo estadístico nacional, que obligan a que solo de manera excepcional una entidad singular se incorpore al listado estando deshabitada. Si al tiempo se tiene presente lo comentado a propósito de la densidad de entidades singulares, surgen serias dudas acerca de la homogeneidad de los criterios de confección del listado mierense, y quizá de concejos aledaños, con los del resto de la región.

Con el fin de enmarcar el adelgazamiento general del poblamiento asturiano, se ha confeccionado un mapa parroquial de variación de población entre 2000 y 2014 (Fig. 3). En él se aprecia la ya mencionada brecha entre población y poblamiento, es decir, entre población y territorio: lo que le ocurre a la mayor parte de la población sucede en un fragmento pequeño del territorio, y a la inversa, hablar de la evolución de la mayor parte de los espacios regionales es abarcar una fracción relativamente pequeña de la población.

Mientras que el conjunto de Asturias ha sufrido un decremento de unas 15.000 personas $(1,4 \%$ de la población inicial), amplias áreas regionales se han quedado en tan sólo 14 años desprovistas de una proporción mucho mayor de sus residentes. Un $56 \%$ del territorio (49\% de las parroquias) había perdido en 2014 como mínimo un $20 \%$ de sus efectivos, sumando casi 42.000 personas 


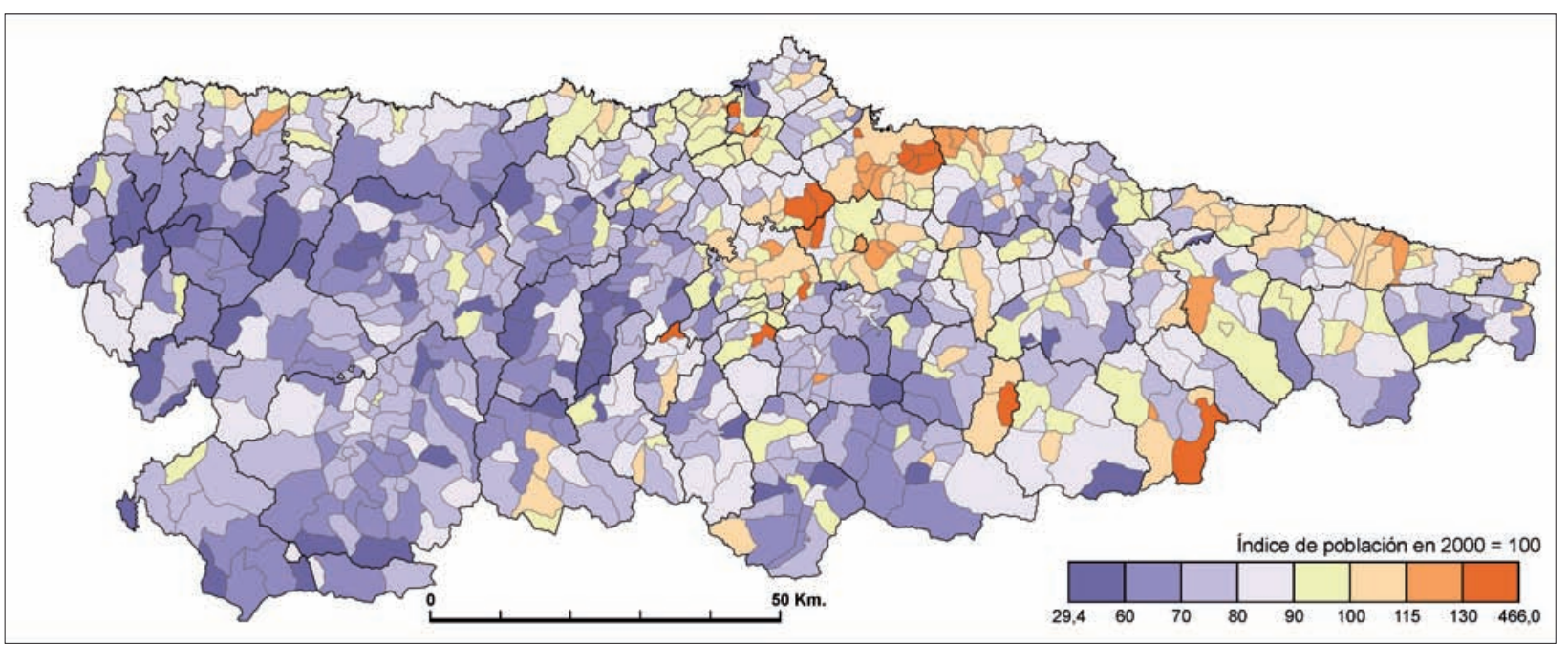

FIG. 3: Variación de población por parroquias, 2000-2014.

menos. Otro $23 \%$ del territorio y de las parroquias conserva todavía el $80 \%$ de la población inicial, perdiendo 18.000 habitantes, en tanto que las parroquias que sólo decrecen como máximo un $10 \%$ en esos 14 años se pueden calificar de afortunadas, con una evolución coherente con la regional.

En este marco recesivo, 121 parroquias consiguen arrojar una evolución positiva, ganando en conjunto unos 55.000 habitantes. Reúnen sólo el $10 \%$ del territorio asturiano, pero acumulan el $60 \%$ de la población.

La oposición entre las áreas rurales y las urbanas, y más concretamente las periurbanas, sigue presente en el mapa que comentamos, concordando con los rasgos ya analizados en distribuciones anteriores. Pero habría que añadir una apostilla sobre el carácter a veces errático de la distribución espacial de esta variable, pues bastantes parroquias de la mitad oriental asturiana, que en muchas ocasiones no coinciden con la capital del concejo, presentan progresos muy aparentes. Téngase en cuenta que tratamos con poblaciones de magnitudes absolutas muy dispares, en las que incrementos de poquísima cuantía pueden pesar proporcionalmente mucho en poblaciones casi exhaustas, como sucede en muchas parroquias de la montaña oriental.

Pero sea como sea, ahí están esas ganancias del oriente, por contraste con la mitad occidental de la región, en la que incluso amplios tramos litorales intercalados entre las capitales de concejo acusan un retroceso. Un examen rápido de los saldos migratorios de los concejos asturianos, única escala espacial para la que es posible su cálculo por diferencia entre el crecimiento real y el natural, revela que incluso en el mar de cifras negativas en que nos movemos siguen produciéndose notorias transferencias espaciales de población, una pequeña parte de las cuales beneficia a los tramos menores de la malla del poblamiento, al menos en los concejos orientales, frente a los occidentales en los que parece que sólo benefician a las capitales de concejo; quizá estemos en buena medida ante inscripciones padronales asociadas a la proliferación de segundas residencias. A este respecto, sería muy interesante un análisis reposado de la Estadística de Variaciones Residenciales, cuyas cifras se publican anualmente provenientes de las altas y bajas padronales por cambios de residencia, otro de los frutos derivados de la implantación reciente del Padrón continuo.

\section{LAS ESTRUCTURAS POR EDAD Y SU PAPEL EN EL DESPOBLAMIENTO}

No es el lugar de desgranar con detalle las causas del retroceso demográfico regional observado más arriba, pero sí es preciso tener presente el ya largo proceso de decadencia de la vitalidad natural asturiana, que durante algún tiempo permaneció velado tras la apariencia enganosa de un simple estancamiento, pero que ha venido realizando sin embargo un soterrado trabajo de zapa cuyos efectos han terminado por manifestarse con rotundidad, trazando hoy un panorama difícilmente reversible.

Desde 1979 la fecundidad no ha asegurado ningún año el reemplazo de las generaciones (el índice coyuntural de fecundidad ha sido inferior a 2 hijos e hijas por mujer), pese a la contribución ligera y momentánea de los inmigrantes en los años anteriores a la crisis econó- 


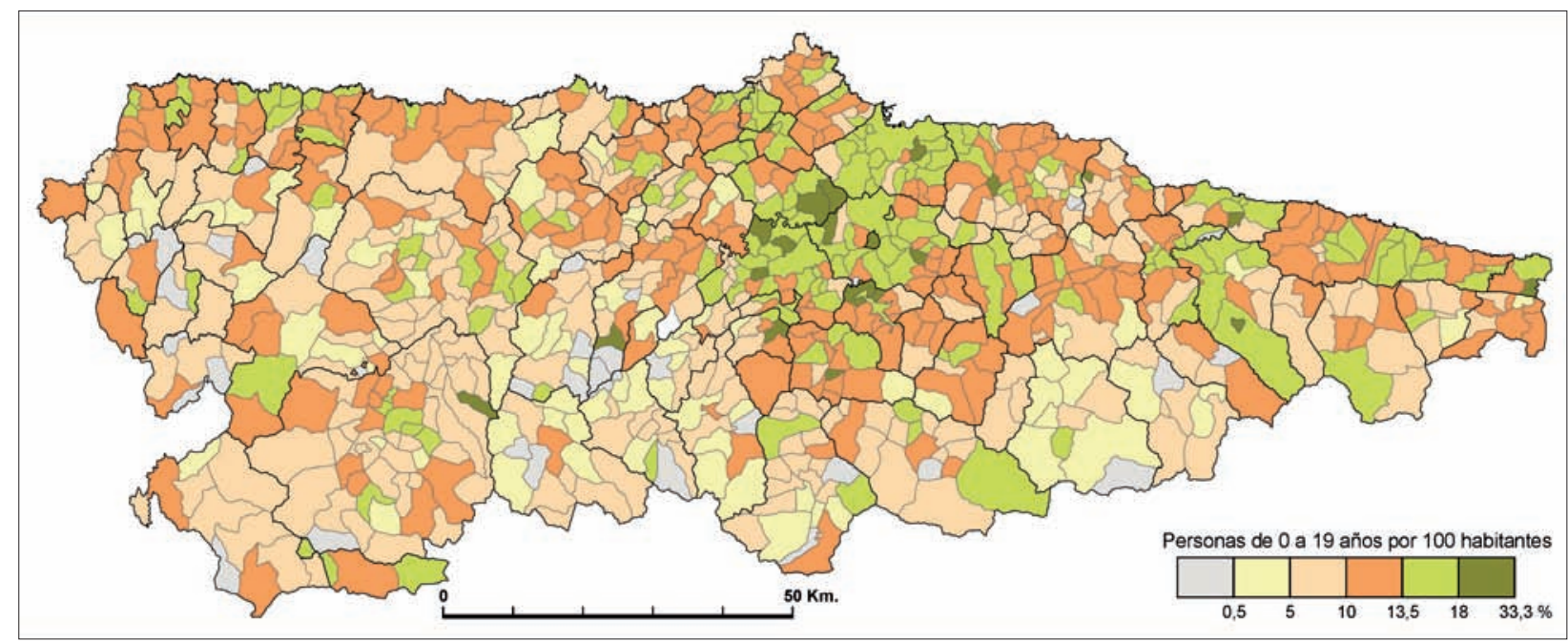

FIG. 4: Proporción de menores de 20 años, 2014.

mica actual. Tampoco las cifras anuales del movimiento natural han dado pie a engaño alguno, pues desde 1985 ha habido un mayor número de defunciones que de nacimientos, exceso que desde 2013 representa ya una merma anual de en torno a 6.000 personas, frente a las cifras modestas del comienzo. La evolución numérica de la población regional, no muy boyante, ha estado por tanto al albur de la llegada o partida de migrantes, velando en ciertos momentos, para quien no quisiera verla, la gravedad de la situación de fondo.

Porque el poso de tres décadas y media de desnatalidad es rotundo, y más si, como sucede desde 1989, raros han sido los años en que la tasa bruta de reproducción ha superado la bajísima cifra de 0,50 (excepto entre 2007 y 2012 por la leve contribución ya comentada de los inmigrantes). Dicho de otro modo, desde hace un cuarto de siglo ha estado naciendo menos de media hija por cada mujer en edad de ser su madre, ocasionando así una contracción drástica del tamaño de las nuevas generaciones. De esta manera se comprende que Asturias se encuentre a la cabeza nacional de los indicadores de envejecimiento, ya que el ciclo desnatalidad-envejecimiento-decrecimiento natural se ha anclado de manera firme en la dinámica regional. Nos engañaríamos si calificásemos esta situación de crisis, con la connotación temporal breve que tal palabra sugiere; estamos ante un verdadero declive.

En esta situación, es inevitable considerar los indicadores del envejecimiento demográfico, no tanto como un medio de vislumbrar qué ha sucedido a la escala espacial de las entidades y parroquias, sino como una manera de entender qué es previsible que suceda en ellas de aquí a unas pocas décadas.
La doble faz del envejecimiento, de un lado la abundancia de personas de edad avanzada, de otro la escasez de jóvenes, atañe a todos los espacios regionales sin excepción, incluidos los urbanos y periurbanos, desmintiendo una hipotética oposición entre un medio rural envejecido y otro urbano, ambos de caracteres demográficos opuestos. Sin la contribución de las poblaciones urbanas la proporción de personas jóvenes, los menores de 20 años, que encarnan el futuro demográfico en ausencia de eventuales migraciones, no alcanzaría en 2014 a representar tan sólo el 14,4\% del total de la población, al tiempo que quienes han acabado sus ciclos vitales asociados a la formación de familias y la reproducción, los mayores de 60 años, no ascenderían al 30,3\%. En medio, algo más de la mitad de la población está en su etapa adulta, aunque la distribución interna de los adultos también refuerza el papel de las edades más elevadas (24\% de ellos están en la veintena y la treintena, $31,2 \%$ en los cuarenta y los cincuenta años).

Observaremos en primer lugar la gradación del envejecimiento a la escala de las parroquias, para luego centrarnos en el análisis de algunas características relativas a las entidades singulares de población, a pesar de que, una vez más, el tamaño a veces minúsculo de las poblaciones entorpezca el cálculo de los indicadores del envejecimiento, por sencillos que éstos sean.

La distribución espacial de los jóvenes y de los viejos (Figs. 4 y 5) muestra de un lado la gravedad del envejecimiento rural, porque cuatro centenares de parroquias (el $46 \%$ de ellas) tienen menos de un $10 \%$ de jóvenes (o carecen de ellos por completo, aunque en esta situación se encuentran sólo 39), en tanto que en seis centenares de 


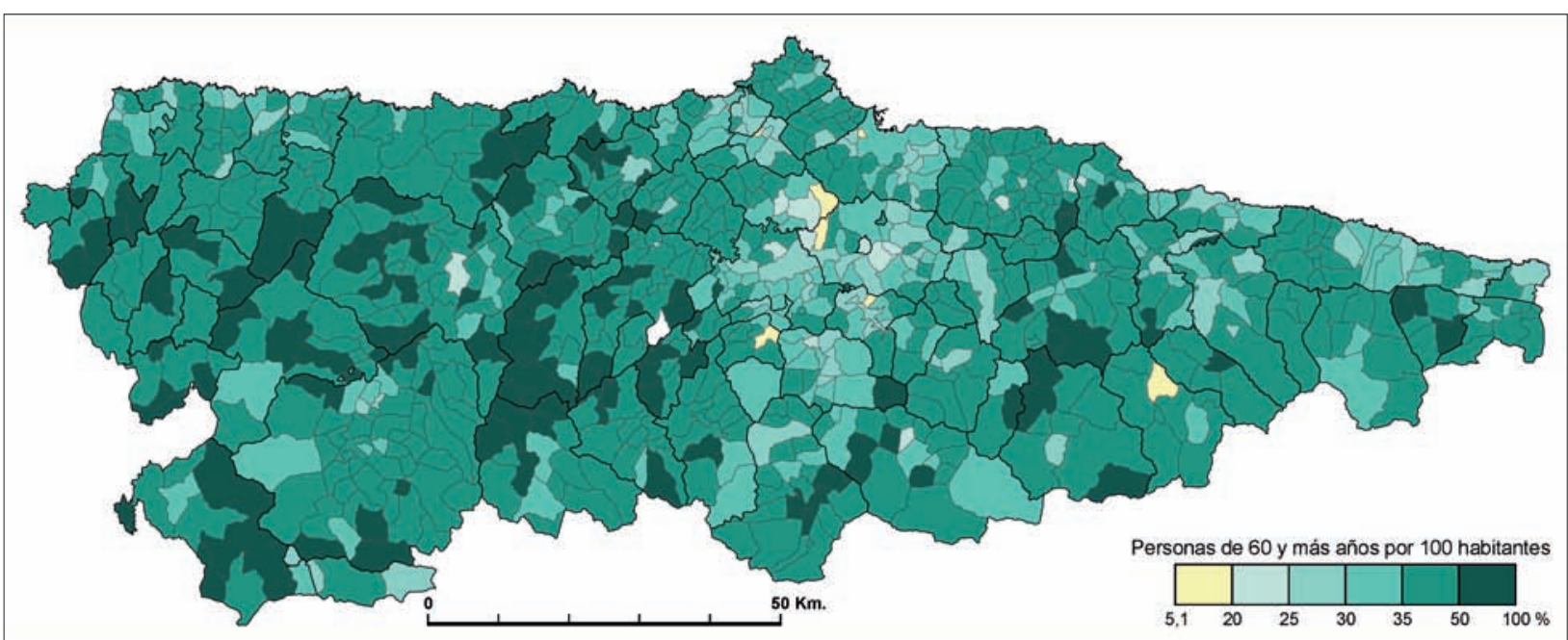

Fig. 5: Proporción de mayores de 60 años, 2014.

parroquias (72\% del total) los mayores de 60 años sobrepasan el $35 \%$, llegando en 129 de ellas a superar más de la mitad de la población. Por comparación con éstas, las parroquias urbanas, y muchas periurbanas del área central, podría decirse que presentan un envejecimiento atenuado, si así pudiera calificarse su composición demográfica en la que casi siempre hay entre un 20 y un $35 \%$ de mayores de 60 años, al tiempo que la proporción de menores de 20 años se encuentra algo por encima de la situación regional, con valores de entre el 13,5 y el $18 \%$.

A lo largo de estas páginas se ha visto reiteradamente cómo la baja densidad, la pérdida de población y finalmente el envejecimiento coincidían en el marco espacial de las parroquias; abordaremos ahora el envejecimiento de las propias entidades singulares, tras haber visto en la matriz de variación con qué frecuencia la erosión demográfica ocurrida en tan sólo 15 años ha acentuado de manera extraordinaria la fragilidad de gran número de ellas.

Con el fin de poner de manifiesto la relación inversa entre tamaño del lugar habitado y envejecimiento, se ha sumado la población de las entidades singulares correspondientes a cinco tamaños distintos, clasificándola a continuación en grupos quinquenales de edad (Fig. 6).

Como es lógico dada la proporción mayoritaria de la población regional que acumulan, las entidades singulares de los dos tramos por encima de 150 habitantes presentan una distribución alineada con la regional, y tanto más «joven» cuanto más elevadas son sus cifras de habitantes. Por el otro extremo desde esta línea divisoria, las entidades de menos de 150 habitantes muestran signos de envejecimiento que se agudizan a medida que se desciende en la gradación de tamaños.
Los dos tramos inferiores, de hasta 50 habitantes, reflejan un envejecimiento difícilmente compatible con su pervivencia a medio y largo plazo. En los 2.056 lugares habitados por menos de 10 personas, cuya población conjunta excede en poco las 9.000 personas, el $47 \%$ de los habitantes supera los 60 años, al tiempo que únicamente el $7 \%$ todavía no ha cumplido 20. En aquellas otras entidades cuya población oscila entre los 10 y los 49 habitantes (2.870 entidades), las proporciones respectivas se alivian un poco, $41 \%$ y $10 \%$. Tanto en un grupo como en el otro, los octogenarios y nonagenarios pesan conjuntamente más que los menores de 20 años, rebasando de largo la proporción 2 a 1 en las entidades más pequeñas. Son lugares castigados por la emigración y la desnatalidad de las décadas pasadas, pero cuya variación demográfica actual se debe al mero balance entre unos nacimientos casi inexistentes y las abundantes defunciones de una población envejecida. Dado que la tabla de mortalidad de Asturias correspondiente a 2014 arroja una esperanza media de vida de 25 años para quienes acaban de cumplir 60 años, y de 9,7 años cuando se acaban de cumplir los $80^{6}$, ese resulta ser el margen temporal de

\footnotetext{
${ }^{6}$ Tan sólo se menciona la esperanza media de vida genérica para ambos sexos, dado que no se ha recogido para las entidades singulares la composición por sexo de manera conjunta con la edad (que el Padrón ofrece clasificada por años individuales de nacimiento y no de manera agregada), lo que hubiera en consecuencia duplicado el ya elevado número de variables incluidas en el análisis. Pero es útil conocer que, para las edades 60 y 80 años cumplidos, los hombres asturianos tienen una esperanza de vida de 22,3 y de 8,3 años respectivamente, en tanto que las mujeres tienen por delante, en promedio, 27,3 y 10,5 años a esas edades. Véase INE: Tablas de mortalidad para provincias y comunidades autónomas, serie 1991-2014, actualizadas en mayo de 2016.
} 


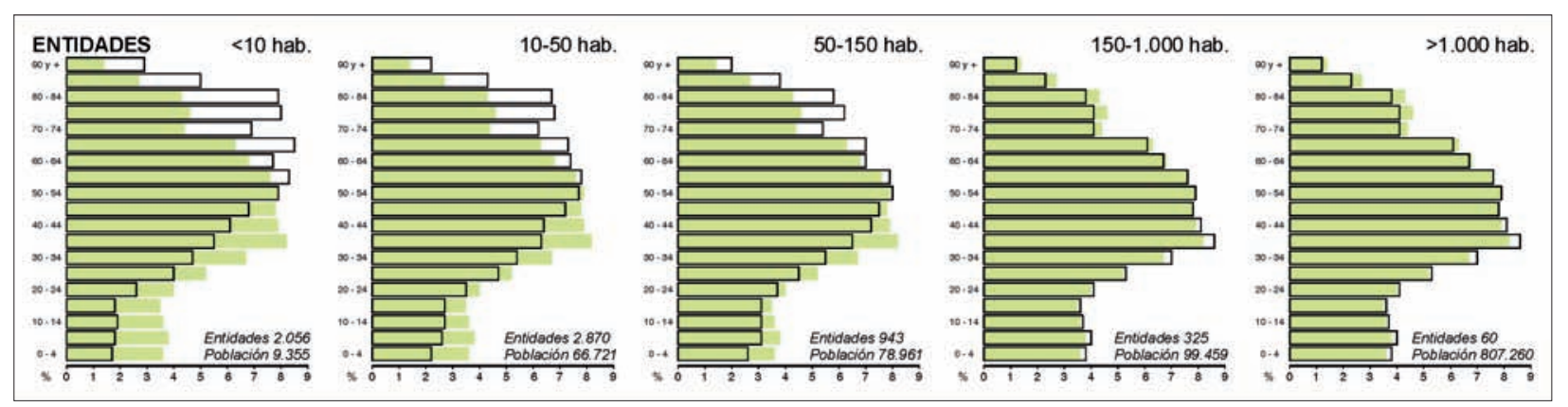

FIG. 6: Distribución por edades de la población de las entidades singulares agrupadas según tamaños, 2014. La silueta sombreada corresponde a la distribución por edades de la población de Asturias.

muchas de estas vulnerables entidades singulares, porque lo es de buena parte de su población, incluso sin la concurrencia de unas migraciones improbables, como no sean los cambios de residencia derivados de la pérdida de la autonomía personal propia de las edades avanzadas.

Ambos tramos inferiores a 50 habitantes suman 4.926 entidades, es decir, casi 8 de cada 10 lugares habitados en Asturias. La suerte del poblamiento asturiano tal como lo hemos heredado de los siglos pasados se decide en ellas.

El umbral mínimo de resistencia del poblamiento, aun en el marco de una situación complicada que augura una involución demográfica cierta, podría quizá situarse en los actuales 50 habitantes por entidad de población ${ }^{7}$. Con una composición por edad no excesivamente peor que la regional, las 80.000 personas que residen en las entidades de entre 50 y 150 habitantes aseguran la pervivencia de este tramo hoy intermedio, pero que a no mucho tardar se convertirá en el nuevo soporte, en la base, del poblamiento regional.

\section{A MODO DE SÍNTESIS}

Hasta ahora los análisis relativos a las entidades singulares se han realizado de forma agregada, omitiendo una localización precisa de las mismas, en la confianza de que el conocimiento paralelo de la situación general de la parroquia proporcionase suficientes indicios sobre

${ }^{7}$ El INE publica regularmente una simulación de los efectos que sobre la población futura tendrían la estructura demográfica y las tendencias demográficas presentes, procediendo a una revisión regular de las proyecciones a medida que varían con el tiempo las tendencias demográficas. Con respecto a Asturias, las proyecciones más recientes ofrecen para el límite temporal de 1 de enero de 2029 una población reducida a 971.000 habitantes, cuya composición sería aún más envejecida que la actual. Véase INE: Proyecciones de Población. Resultados por comunidades autónomas y provincias, serie 2014-2029, publicadas en octubre de 2014. la distribución espacial de los riesgos de despoblamiento asociados al envejecimiento.

No obstante, nos hemos propuesto realizar un intento de localización de aquellas parroquias en las que una parte importante de sus lugares habitados están en grave riesgo de vaciamiento, bien porque su población se encuentre muy envejecida, bien porque sean de tamaño excesivamente pequeño. Como es obvio, se trata de un análisis muy parcial de la situación del poblamiento, que da preferencia al aspecto espacial o geográfico del cambio que se avecina, dejando en segundo plano la evaluación de su alcance demográfico, dado que en este trabajo no se ha acometido el necesario análisis de las formas, o estructura, del poblamiento parroquial.

A la luz de los análisis agregados que hasta ahora se han realizado sobre las entidades singulares, hemos definido dos criterios de alta vulnerabilidad para éstas. En primer lugar, se ha considerado que cuando la mitad o más de la población de una entidad singular tiene una edad superior a 59 años, dicha entidad está sobreenvejecida; en segundo lugar, que cuando una entidad cuenta con menos de 10 habitantes, tiene un tamaño demasiado frágil. A continuación se ha calculado la proporción de entidades de cada parroquia en cada una de esas dos situaciones, y elaborado una cartografía conjunta (Fig. 7). En ella se establecen dos niveles de riesgo para cada criterio: si afecta a la mitad o más de las entidades de la parroquia el riesgo es máximo, si lo hace a una proporción de entre el 40 y el $50 \%$ de los lugares habitados, se considera un riesgo algo más atenuado o medio, que es todavía menor cuando la proporción baja del $40 \%$. Cabe finalmente la posibilidad de que una parroquia solo tenga entidades en riesgo considerando uno solo de los dos criterios, y en ese caso se ha dado preferencia al envejecimiento sobre la debilidad numérica de los habitantes, ésta mucho más dependiente de la estructura del poblamiento de los concejos, y en cierto modo también de la definición que éstos 


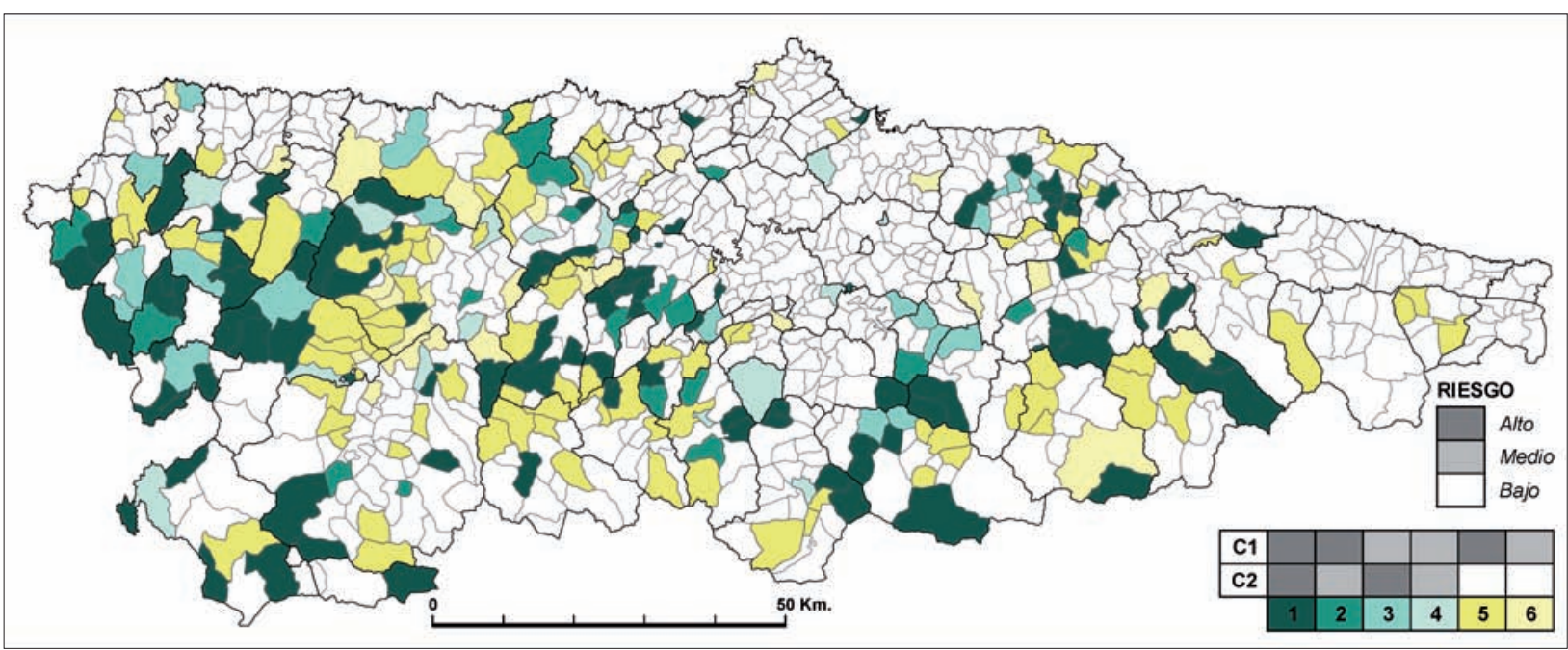

FIG. 7: Vulnerabilidad de las entidades singulares de las parroquias, 2014. C1: criterio de vulnerabilidad asociada al envejecimiento: como mínimo, la mitad de la población de la entidad es mayor de 59 años. C2: criterio de vulnerabilidad derivada del tamaño reducido de la entidad singular: ésta tiene menos de 10 habitantes. Riesgo alto: el criterio afecta a la mitad o más de las entidades de una parroquia. Riesgo medio: el criterio afecta a una proporción de entre el 40 y el $50 \%$ de las entidades de una parroquia. Riesgo bajo: el criterio afecta a menos del $40 \%$ de las entidades de la parroquia.

hacen del listado de entidades, en tanto que el criterio del envejecimiento proporciona una información irrefutable.

En el mapa se encuentran representadas 287 parroquias, aquellas en las que, como mínimo, el sobreenvejecimiento afecta al $40 \%$ de sus lugares habitados, lo que quiere decir que exactamente un tercio de las parroquias asturianas se encuentra englobado en esta situación. Dentro de este conjunto, la situación más frecuente (221 entidades colectivas) es la de máximo riesgo, es decir, cuando el sobreenvejecimiento aqueja a más de la mitad de las entidades ${ }^{8}$.

Por el lado de la escasez de habitantes, en 249 parroquias la proporción de entidades de menos de 10 habitantes supera el $40 \%$ del total de entidades, pero no todas esas parroquias han sido llevadas al mapa, pues se han omitido 93 en las que el paralelo y prioritario criterio del envejecimiento no alcanza el nivel medio de riesgo. Bastantes parroquias situadas en las áreas que hemos señalado con una elevada densidad de entidades no han sido incluidas en el mapa por esa razón.

Aclarado pues el hecho de que, afortunadamente, la mayor parte del mapa aparezca vacío, resta por considerar la distribución espacial reflejada en el mismo. En el área central y las marinas, las parroquias tienen, salvo

\footnotetext{
8 Aunque no quede reflejado en el mapa, se podría precisar aún más, y mencionar que en 44 parroquias la totalidad de sus lugares habitados se halla en esta situación extremadamente vulnerable.
}

esporádicamente, bajo riesgo de perder una parte importante de sus entidades debido al envejecimiento y la consiguiente despoblación, lo mismo que en los concejos del área central. Cabría citar como excepciones relevantes las áreas de algunos concejos litorales situadas hacia el interior, sobre las sierras prelitorales, como ocurre en Villaviciosa, Cudillero y Valdés. También es posible que vean desaparecer una parte de sus entidades las parroquias de los altos valles y cordales de los concejos del centro de la región, como en Lena, Aller, San Martín del Rey Aurelio y Laviana porque, entre otras razones, sus listados de entidades singulares están profusamente poblados, casi más de topónimos que de personas.

Es de destacar que la montaña del oriente asturiano está poco representada en este mapa de riesgos, excepto el concejo de Amieva, que aparece incluido al completo, debido a que su poblamiento consta de entidades de tamaño mayor al definido aquí como excesivamente frágil, aunque sus poblaciones no estén menos envejecidas que otras áreas de alta y media montaña. Así y todo, los concejos de Caso, Sobrescobio, Ponga, Onís y Peñamellera Alta cuentan en conjunto con bastantes parroquias en situación vulnerable.

Pero, qué duda cabe, lo más revelador del mapa es la situación en que se encuentra la mitad occidental de Asturias. Concejos enteros y la mayor parte de otros entran dentro de alguna de las situaciones de riesgo de despoblamiento, con mucha frecuencia en su grado más alto. Al completo se encuentran algunos del extremo su- 
roccidental, como Illano, y dos de los tres concejos de la comarca de los Oscos, San Martín y Santa Eulalia, en tanto que los de Allande, Taramundi, Grandas de Salime y Tineo proporcionan a este mapa de riesgo de despoblamiento más del $70 \%$ del su territorio. En un grado algo menor, pero siempre por encima del tercio de sus parroquias, están los concejos de Salas, Boal, Ibias, Villanueva de Oscos, Cangas del Narcea, Degaña y Villayón.

Un último foco de despoblamiento posible lo constituyen los concejos de la media montaña al este del valle del Narcea, en especial Belmonte de Miranda, cuyas parroquias en riesgo cubren los dos tercios de su territorio, mientras que en Grado y en Somiedo la proporción oscila entre el $40 \%$ y la mitad.

En una sociedad fuertemente urbanizada, como lo es la española en la actualidad, estamos presenciando el final de un largo ciclo de evolución del poblamiento rural; tras el debilitamiento, se avecina la desaparición física de buena parte de los lugares de asentamiento cuya razón de ser ha sido durante siglos la precaria explotación agraria del espacio, que en el caso de Asturias ha sido casi siempre un territorio fragmentado, organizado en terrazgos de extensión reducida, necesitado pues de un poblamiento muy disgregado. El vaciamiento rural al que asistimos desde hace tantas décadas representa ya la pérdida de un inmenso patrimonio, tangible e intangible, que sin embargo va camino de agrandarse todavía.

En este trabajo se han perfilado tanto la dimensión absoluta del riesgo de despoblamiento en Asturias, como los grandes rasgos de su distribución espacial. Pero resta por conocer la estructura del poblamiento, y la función que ejerce cada elemento del mismo, para identificar aquellas unidades del mismo que permitan todavía una ocupación del espacio, menor y distinta a la que ahora peligra, pero ocupación al fin y al cabo.

Una vasta extensión de territorio va a cambiar radicalmente de uso de aquí a unas pocas décadas, cuando los asturianos ya no residan en los pueblos pequeños sino en las ciudades, villas y cabeceras comarcales. Los cambios ya se leen en el paisaje actual, pero todavía queda por delante un reto extraordinario, el de dar uso y hacer frente al mantenimiento de un espacio al que va a ser necesario encontrar otra utilidad, más allá de la omnipresencia de las plantaciones de eucalipto.

\section{FUENTES Y BIBLIOGRAFÍA}

Fernández Cuesta, G. (dir.), J. C. Castañón Álvarez, A. Colina Vuelta, J. R. Fernández Prieto y A. Olaizola FERnÁNDEZ (2005): Atlas escolar de Asturias. Ediciones Nobel, Oviedo, 174 pp.

Fernández García, A. (coord.) (2007): Población, administración y territorio en Asturias. Consejo Económico y Social del Principado de Asturias, 198 pp.

Fernández García, F., y G. Morales Matos (1983): «El poblamiento», en F. Quirós Linares (dir.): Geografía de Asturias. Vol. 4, Ayalga, Salinas, 1983, pp. 270-277.

Instituto Nacional de Estadística: Estadística del Padrón Continuo. Sistema de Información Demográfica del Padrón, datos referidos a 1 de enero de 2014.

- Nomenclátor: Población del Padrón Continuo por unidad poblacional, serie 2000-2014.

- Proyecciones de Población. Resultados por comunidades autónomas y provincias, serie 2014-2029, publicadas en octubre de 2014.

- Tablas de mortalidad para provincias y comunidades autónomas, serie 1991-2014, actualizadas en mayo de 2016.

- Movimiento Natural de la Población. Resumen municipal, serie 2000-2014.

LóPEZ FERNÁNDEZ, B. (2010): «La población», en G. Fernández Cuesta y F. Quirós Linares (dirs.): Atlas Temático de España. Vol. 2, pp. 11-155.

Pérez GonzÁlez, R. (1983): «La población de Asturias», en F. Quirós Linares (dir.): Geografía de Asturias. Vol. 4, Ayalga, Salinas, 1983, pp. 234-269.

Quirós Linares, F. (1993): División Parroquial de Asturias. Servicio Central de Publicaciones del Principado de Asturias, 78 pp., 1 lám.

- (1982): «La delimitación territorial de las parroquias asturianas». Ería, núm. 3, pp. 79-82. 